\title{
Loop technique with ink-dot marking test: An alternative strategy to the ink test
}

\author{
Akimasa Morisaki, MD, PhD, ${ }^{\mathrm{a}}$ Yosuke Takahashi, MD, PhD, ${ }^{\mathrm{a}}$ Hiromichi Fujii, MD, PhD, ${ }^{\mathrm{a}}$ \\ Yoshito Sakon, MD, PhD, ${ }^{a}$ Takashi Murakami, MD, PhD, ${ }^{b}$ and Toshihiko Shibata, MD, $\mathrm{PhD}^{\mathrm{a}}$
}

\section{ABSTRACT}

Objective: We assessed the long-term outcomes of the loop technique with the ink-dot marking test, an alternative to the ink test for aligning the mitral valve (MV) leaflet height, during MV repair.

Methods: We retrospectively reviewed 351 patients who underwent MV repair with the loop technique via median sternotomy or right mini-thoracotomy. The ink-dot marking test involves creation of a dotted line between the rough and clear zones in the anterior leaflet and the center of the posterior leaflet by gentian violet. According to this marking, we adjusted the fixing position of the loops with or without the loop-in-loop technique and additional neochordal repair.

Results: This study involved 141 women and 210 men (mean age, $63.7 \pm 13.0$ years). Forty-one patients required additional adjustment after the ink-dot marking test. No significant differences were found in the need for second arrest between patients who did and did not require additional adjustment after the ink-dot marking test (3 vs 32 patients, $P=.782$ ). Predischarge transthoracic echocardiography showed trivial residual MV regurgitation (MR) in 285 patients, mild in 64, and moderate in 2. Ten patients needed reoperations (9 MV replacements and $1 \mathrm{MV}$ rerepair) because of recurrent MR during postoperative follow-up. The $3^{-}, 5^{-}$, and 10-year postoperative cumulative incidence of moderate to severe recurrent MR was $3.6 \%, 6.0 \%$, and $19.8 \%$, respectively.

Conclusions: The loop technique with the ink-dot marking test provided good early and long-term results. This test may help to decrease residual MR, especially when using the loop technique. (JTCVS Techniques 2020;3:110-21)

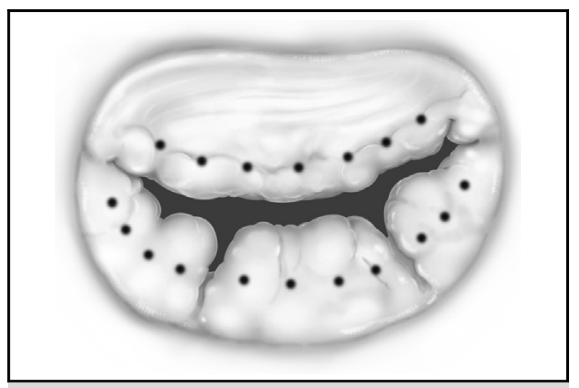

Ink-dot marking test with a dotted line on the anterior leaflet and the posterior leaflet.

\section{CENTRAL MESSAGE}

Intraoperative assessment tools are important for excellent earlyand long-term results of mitral valve repair. What such tools should we use to obtain good long-term results of the loop technique?

\section{PERSPECTIVE}

We assessed the outcome of the loop technique using the intraoperative ink-dot marking test. The mitral valve leaflet height was aligned by adjusting the fixing position of the loops according to inkdot markings between the rough zone and clear zone in the anterior leaflet and at the center of the posterior leaflet. This technique showed excellent long-term results for mitral valve regurgitation.

See Commentaries on pages 122 and 124 .
From the a Department of Cardiovascular Surgery, Osaka City University Graduate School of Medicine; and ${ }^{\mathrm{b}}$ Department of Cardiovascular Surgery, Osaka City General Hospital, Osaka, Japan.

Received for publication April 29, 2020; revisions received April 29, 2020; accepted for publication May 8, 2020; available ahead of print May 16, 2020.

Address for reprints: Akimasa Morisaki, MD, PhD, Department of Cardiovascular Surgery, Osaka City University Graduate School of Medicine, 1-4-3 Asahimachi, Abeno-ku, Osaka 545-8585, Japan (E-mail: m3_514@yahoo.co.jp).

2666-2507

Copyright $@ 2020$ The Authors. Published by Elsevier Inc. on behalf of The American Association for Thoracic Surgery. This is an open access article under the CC BY-NC-

ND license (http://creativecommons.org/licenses/by-nc-nd/4.0/).

https://doi.org/10.1016/j.xjtc.2020.05.010 $\square$ Video clip is available online.

Mitral valve (MV) repair is the gold standard treatment for MV regurgitation (MR). Various repair techniques, such as resection and suture techniques, neochordal repair, the loop technique, and the Alfieri stich, have shown good long-term outcomes. ${ }^{1-4}$ A new paradigm shift from resection and suturing to neochordal repair to posterior leaflet prolapse ("respect rather than resect") was recently described. ${ }^{5} \mathrm{MV}$ 


\section{Abbreviations and Acronyms \\ ePTFE $=$ expanded polytetrafluoroethylene \\ MR = mitral valve regurgitation \\ MV = mitral valve}

repair with neochordal repair to the anterior and posterior leaflets provides better leaflet mobility and coaptation of the MV leaflet than resection and suturing, which is associated with a low MV pressure gradient. ${ }^{6,7}$ Furthermore, Oppell and $\mathrm{Mohr}^{8}$ reported that the loop technique with expanded polytetrafluoroethylene (ePTFE) is easy, adjustable, and reproducible. We performed the loop technique and attained good mid-term outcomes. ${ }^{9}$

More-than-mild residual MR is an independent factor associated with more-than-moderate recurrent MR and reoperations. ${ }^{1,3,4}$ Therefore, the absence of intraoperative residual MR is a key factor for durable repair. A saline test during cardiac arrest after MV repair is commonly performed to identify residual MR. However, larger-thanexpected residual MR after weaning of cardiopulmonary bypass is sometimes detected by the saline test and may require additional interventions. Good MV configuration as indicated by the so-called "smiley face" is another key factor for successful repair with good coaptation of the MV leaflets, which should be connected to decrease residual MR. Anyanwu and Adams ${ }^{10}$ described the "ink test" for MR during MV repair. This method only involves ensuring an adequate coaptation length, which is associated with a decreased incidence of residual MR. We have used the ink-dot marking test as an alternative because good configuration of the MV can be obtained by adjusting the length and fixing point of the loop. In this study, we retrospectively assessed the outcomes of the loop technique with the ink-dot marking test for MR.

\section{METHODS}

\section{Patients}

We retrospectively evaluated 351 patients who successfully underwent MV repair with the loop technique via a median sternotomy or right minithoracotomy at Osaka City University Hospital and Osaka City General Hospital from April 2008 to April 2018. This study was approved by the institutional review board of Osaka City Medical School Hospital and Osaka City General Hospital (Clinical trial registry number: 4378) and complied with current ethical guidelines according to the Declaration of Helsinki. Individual consent for the later retrospective study was obtained simultaneously with consent for the cardiovascular surgery.

Preoperative renal insufficiency was defined as a creatinine level of $>1.5 \mathrm{mg} / \mathrm{dL}$. Preoperative pulmonary disease in this study was equivalent to chronic obstructive pulmonary disease, including emphysema and bronchial asthma treated with steroids. Postoperative renal failure was defined as a creatinine level of $>2.0 \mathrm{mg} / \mathrm{dL}$ or a $>1.5$-fold increase in creatinine above the preoperative level and a requirement for hemodialysis. Postoperative myocardial infarction was diagnosed by new left ventricular wall asynergy, a continuous increase in creatine kinase-MB or troponin, and postoperative electrocardiographic changes consisting of ST changes or a new $\mathrm{Q}$ wave in 2 or more leads. Barlow's disease has a distinctive macroscopic appearance characterized by an advanced stage of excess myxomatous degeneration of the leaflets, including bileaflet prolapse, billowing, chordal elongation, and annular dilatation with or without calcification. This is in contrast to fibroelastic deficiency, which mainly includes limited prolapsing segments.

Tricuspid repair was performed in patients with more-than-moderate tricuspid regurgitation and in those with mild tricuspid regurgitation with atrial fibrillation, pulmonary hypertension, or annular dilatation.

\section{Surgical Techniques}

The technical procedures used in the conventional approach and the right mini-thoracotomy approach (minimally invasive cardiac surgery) of the present study are described in full detail in the Appendix 1.

\section{Repair With Loop Technique and Ink-Dot Marking Test}

We performed MV repair with the loop technique as previously described. $^{9}$ First, we identified the MR lesion with the prolapsed area and assessed the corresponding papillary muscle. We then measured the required length of the ePTFE loop based on the distance between the correct plane apposition on the non-prolapsing segment, near the ruptured or elongated chorda, and the head of the corresponding papillary muscle as a reference using a chordal gauge (Arvadec, Tokyo, Japan). The loop set was part of the Shibata Chordae System (Geister Inc, Tuttlingen, Germany) with a CV5 or CV4 ePTFE suture (Gore-Tex; W. L. Gore \& Associates, Flagstaff, Ariz) and a felt pledget. The number of loops depended on the prolapse area (more than 2 loops). The loop set was fixed on the corresponding papillary muscle with the ePTFE suture needles. Next, the loops were affixed to the edge of the prolapsing segment using 5-0 PROLENE (Ethicon, Cincinnati, Ohio) in a figure-of- 8 fashion from the left ventricular side to the atrial side doubly. We also performed the loop-in-loop technique or neochordal repair with fixing suture needles as appropriate to align the leaflet height. The fixing suture needles consisted of the ePTFE suture needles fixing the loop set on the papillary muscle (Figure 1). Height reduction was performed for patients with a large posterior leaflet of more than 20 to $25 \mathrm{~mm}$ to prevent systolic anterior leaflet motion. Autologous patch augmentation was performed to shorten the posterior leaflet and thus obtain

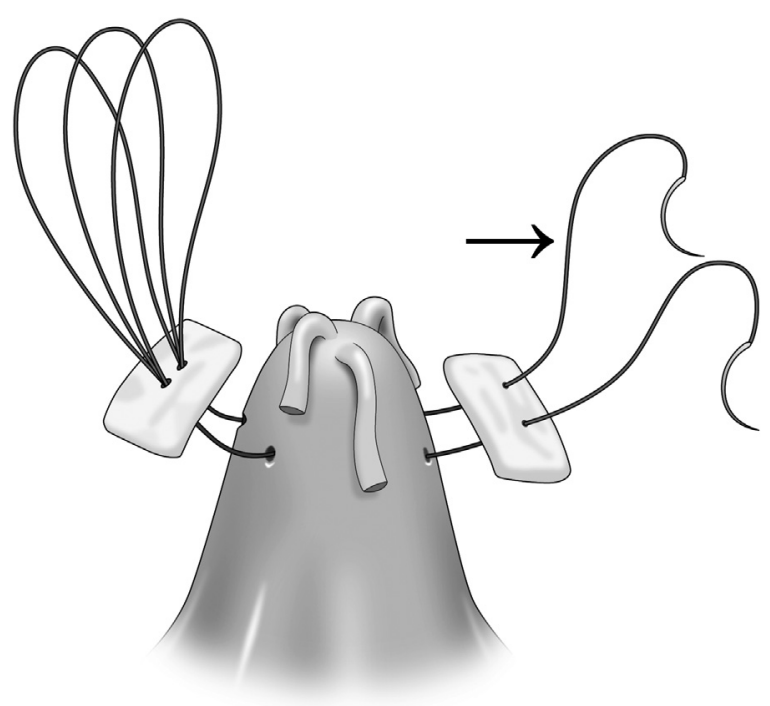

FIGURE 1. Loop technique. The solid arrow indicates the fixing suture needles. 
an adequate coaptation length. Commissural edge-to-edge suturing and resection and suturing were performed adequately. After the loop technique, mitral annular repair with a semirigid total ring (Carpentier-Edwards Physio annuloplasty ring [ $\mathrm{n}=45]$ or Physio II annuloplasty ring $[\mathrm{n}=300]$; Edwards Lifesciences, Irvine, Calif), a semi-rigid partial ring (CosgroveEdwards Annuloplasty System [n=1]; Edwards Lifesciences), a rigid ring (SJM rigid saddle ring $[\mathrm{n}=2]$; Abbott Laboratories, Chicago, Ill), or a flexible total ring (Tailor Flexible Ring [ $\mathrm{n}=2$ ]; Abbott Laboratories) was performed in the conventional fashion, except for 1 patient, because a suitable ring size was not available for the mitral annular size.

We marked a dotted line between the rough zone and clear zone in the anterior leaflet and the center of the posterior leaflet using gentian violet (Pyoktanin; Sigma-Aldrich, St Louis, Mo) (Figure 2, $A$ and $B$, and Video 1). We then identified the alignment of the leaflet height by the saline injection test and adjusted the fixing position of the loops, or we additionally performed the loop-in-loop technique or neochordal repair with fixing suture needles to align the MV leaflet height with minimal leakage and a good coaptation length according to the ink-dot markings (Figure 3, $A$ and $B$, and Video 1).

\section{Follow-up}

All patients underwent postoperative transthoracic echocardiography before discharge. Excluding patients who died during hospitalization and those who underwent MV replacement for left ventricular rupture, the patients were followed up on an outpatient basis every 6 to 12 months. More-than-moderate-to-severe residual MR was defined by transthoracic echocardiography or transesophageal echocardiography. We followed up 331 patients on an outpatient basis, and those who were lost to follow-up were censored at the point of the last known undergoing echocardiography for recurrent MR and the last known visiting the hospital.

\section{Statistical Analysis}

Data were analyzed using the statistical software EZR version 1.41 (Saitama Medical Center, Jichi Medical University, Saitama, Japan) based on R and R Commander (The R Foundation for Statistical Computing, Vienna, Austria). More precisely, EZR is a modified version of R Commander (version 2.6-1) designed to add statistical functions frequently used in biostatistics. Numerical variables are expressed as median (interquartile range) or mean \pm standard deviation. Categorical variables are expressed as number and percentage and were compared using the Fisher exact test. The postoperative reoperation rates are expressed as the cumulative incidence with death as the competing variable. The differences in the cumulative incidence between 2 or 3 groups were evaluated by Gray's test. The postoperative rates of more than moderate-to-severe recurrent MR are expressed the cumulative incidence. The differences in the cumulative incidence between 2 or 3 groups were evaluated by the log rank test.

\section{RESULTS}

Table 1 summarizes the patients' characteristics. Their mean age was $63.7 \pm 13.0$ years (median [interquartile range], 66.0 [57.0-73.0] years). The patients comprised 141 women and 210 men. Among the patients with chronic renal dysfunction, 3 required hemodialysis. Eighty patients had chronic or persistent atrial fibrillation. The preoperative cardiac operations included coronary artery bypass grafting in 2 patients, MV repair with resection and suturing in $1 \mathrm{pa}-$ tient, and an operation for an endocardial cushion defect in 1 patient. The MR was caused mainly by degenerative changes in 293 patients, Barlow's disease in 22, atriogenic and degenerative changes in 12 , infective endocarditis in 17 , ischemic disease in 3 , rheumatic disease in 3 , and another cause in 1 . The main lesion of the MV involved the anterior leaflet in 78 patients, posterior leaflet in 163 , and bilateral leaflets in 110 .

Table 2 summarizes the intraoperative data. The MV repair was performed through a median sternotomy in 283 patients and through a mini-right thoracotomy in 68 . The mean number of loops was $3.3 \pm 1.7$ per patient (median [interquartile range], 3 [2-4] per patient). Additional MV

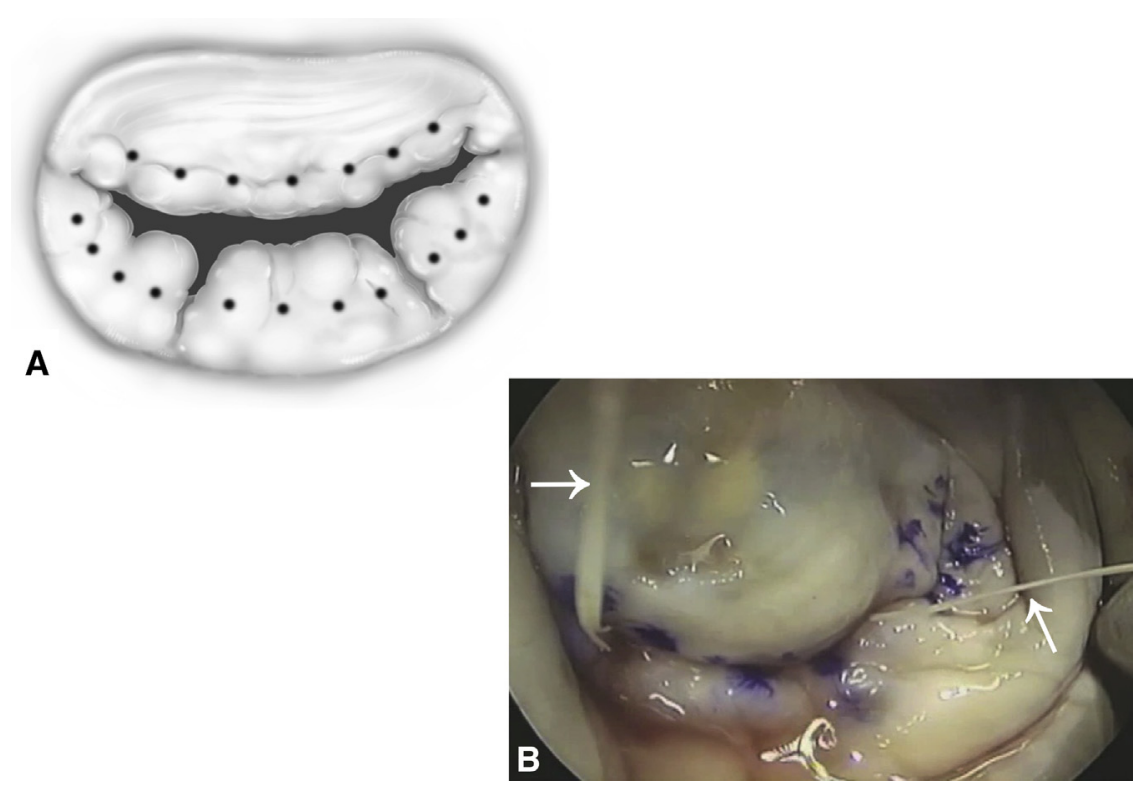

FIGURE 2. Ink-dot marking test. A dotted line is marked between the rough zone and clear zone in the anterior leaflet and the center of the posterior leaflet using gentian violet (Pyoktanin; Sigma-Aldrich). A, Schema. B, Intraoperative findings. The solid arrow indicates the fixing suture needles. We identified the appropriate alignment of the leaflet height by the ink-dot marking under saline injection. 


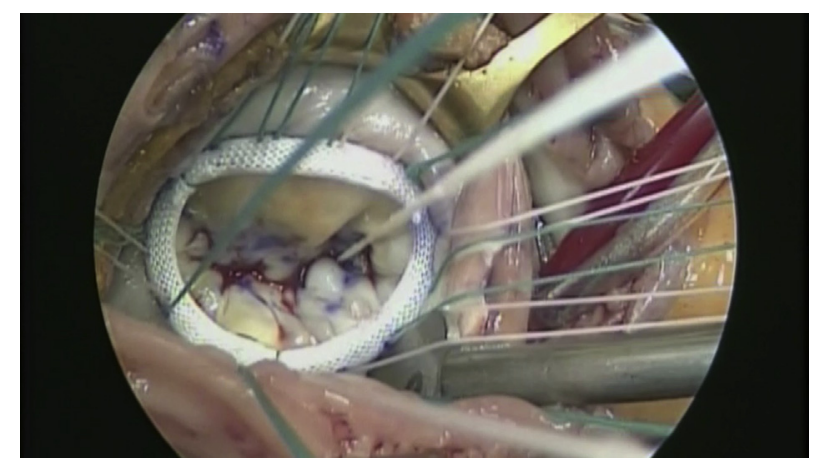

VIDEO 1. Loop technique with ink-dot marking test for posterior leaflet prolapse. First, we identified the MR lesion with the prolapsed area and assessed the corresponding papillary muscle. We then established the loop set (2 loops) with ePTFE based on the distance between the correct plane apposition on the non-prolapsing segment, near the ruptured or elongated chorda, and the head of the corresponding papillary muscle as a reference. The loop set was fixed on the corresponding papillary muscle with the ePTFE suture needles. Next, the 2 loops were affixed to the edge of the prolapsing posterior leaflet segment using 5-0 PROLENE in a figure-of-8 fashion from the left ventricular side to the atrial side doubly. We marked a dotted line between the rough zone and clear zone in the anterior leaflet and the center of the posterior leaflet using gentian violet (Pyoktanin; Sigma-Aldrich). After the ink-dot marking, we assessed the alignment of the leaflet height by the saline injection test. After mitral valve annuloplasty, we reassessed the alignment of the leaflet height by the saline injection test. This test showed the residual prolapsing posterior leaflet segment, which required adjustment of the fixing position of the loop. We then performed additional neochordal repair with the fixing suture needles because reassessment by the saline injection test showed slight prolapse of the residual segment. Finally, we confirmed good coaptation and alignment of the leaflet height by the saline injection test. Video available at: https:// www.jtcvs.org/article/S2666-2507(20)30231-5/fulltext.

repair techniques were commissural edge-to-edge suturing in 232 patients, the loop-in-loop technique in 87, fixing suture needles in 71 , secondary chordal cutting in 11 , height reduction in 25 , patch augmentation in 8 , and triangular resection in 4 . Forty-one patients required additional adjustment of fixing the loops, the loop-in-loop technique, or fixing suture needles after the ink-dot marking test. Thirty-five patients $(10.0 \%)$ required a second arrest with additional repair because of more-than mild-to-moderate residual MR on intraoperative transesophageal echocardiography. No significant differences were found in the requirement for second arrest between patients who did and did not require additional adjustment ( 3 vs 32 patients, $P=.782$ ). Finally, we finished the operations in all patients with lower-than-mild residual MR on intraoperative transesophageal echocardiography. In total, 121 patients underwent tricuspid valve repair concomitantly. Fourteen patients had systolic anterior leaflet motion, which improved by height reduction in 3 patients and volume overload in 11 patients. Four patients required intra-aortic balloon pumping because of low output syndrome $(\mathrm{n}=3)$ and left ventricular rupture $(n=1)$ intraoperatively. The median operation time, cardiopulmonary bypass time, and aortic crossclamp time are also shown in Table 2.

\section{Early-Term Outcomes During Hospitalization}

The 30-day mortality was only $0.3 \%$ (1 patient died of septic shock secondary to rectal ulceration). Forty-three patients $(12.3 \%)$ had morbidities (Table 2). Seven patients required re-exploration for bleeding. Five patients had postoperative myocardial infarction. Among them, 2 patients who undergone MV repair through the median sternotomy and the right mini-thoracotomy required coronary artery bypass grafting because of circumflex artery stenosis or occlusion by MV repair. Three patients with no preoperative ischemic diseases, who undergone MV repair through the median sternotomy, developed left ventricular free wall rupture (intraoperatively and on postoperative days 1 and 9, respectively). Among them, the patient who developed the rupture on postoperative day 9 underwent left ventricular repair and MV replacement with a mechanical valve for left ventricular rupture caused by acute myocardial
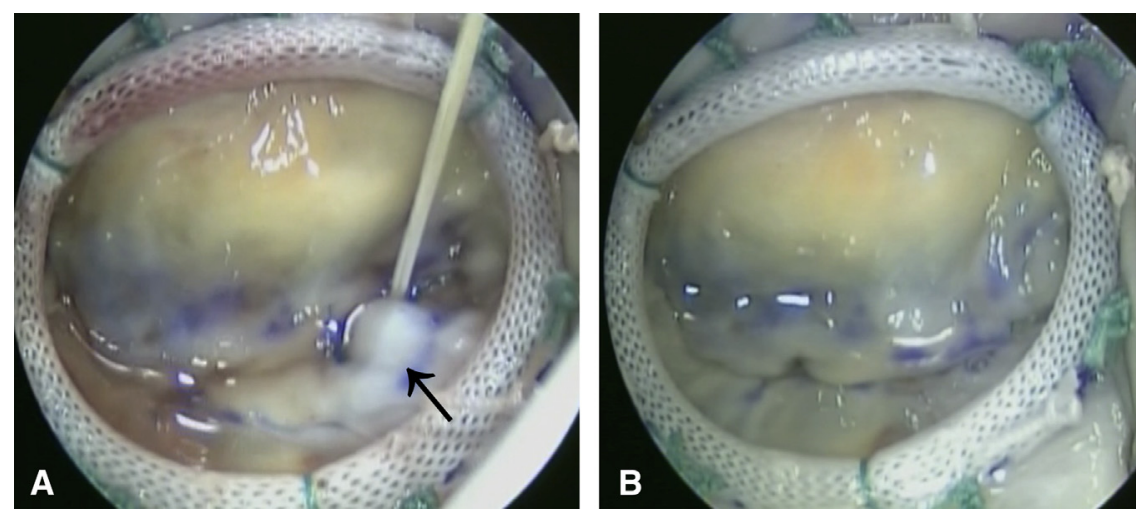

FIGURE 3. Adjustment of loop technique according to ink-dot marking test. A, Saline injection with the ink-dot marking test before adjustment of repair. The image shows residual prolapse of the middle posterior leaflet without major leakage (solid arrow). B, Saline injection test after adjustment of repair with repositioning of the fixing loop and additional neochordal repair. The image shows appropriate alignment of the leaflet height. 
TABLE 1. Patients' preoperative characteristics

\begin{tabular}{|c|c|}
\hline \multicolumn{2}{|l|}{ Variable } \\
\hline Age, y & $66.0(57.0-73.0)$ \\
\hline Sex, female/male & $141(40.2) / 210(59.8)$ \\
\hline BMI, $\mathrm{kg} / \mathrm{m}^{2}$ & $22.0(19.6-24.2)$ \\
\hline BSA, $m^{2}$ & $1.6(1.48-1.71)$ \\
\hline Hypertension & $190(54.1)$ \\
\hline Hyperlipidemia & $92(26.2)$ \\
\hline Diabetes mellitus & $26(7.4)$ \\
\hline Smoking & $86(24.5)$ \\
\hline Renal dysfunction, $\mathrm{Cr}>1.5 \mathrm{mg} / \mathrm{dL}$ & $26(7.4)$ \\
\hline Hemodialysis & $3(0.9)$ \\
\hline Cerebrovascular disease & $19(5.4)$ \\
\hline Respiratory disease & $29(8.3)$ \\
\hline Liver disease & $16(4.6)$ \\
\hline Peripheral vascular disease & $8(2.3)$ \\
\hline Atrial fibrillation & $80(22.8)$ \\
\hline Preoperative ejection fraction, $\%$ & $65.0(60.0-69.0)$ \\
\hline Preoperative ejection fraction of $<40 \%$ & $6(1.7)$ \\
\hline Preoperative LV diastolic dimension, $\mathrm{mm}$ & $54.0(49.3-58.0)$ \\
\hline $\begin{array}{l}\text { Preoperative LV diastolic dimension } \\
\quad \text { of }>65 \mathrm{~mm}\end{array}$ & $18(5.1)$ \\
\hline NYHA class $>$ III & $63(17.9)$ \\
\hline Previous cardiac surgery & $4(1.1)$ \\
\hline \multicolumn{2}{|l|}{ Cause of mitral valve regurgitation } \\
\hline Degenerative change & $293(83.5)$ \\
\hline Barlow's disease & $22(26.3)$ \\
\hline Atriogenic and degenerative & $12(3.4)$ \\
\hline Infective endocarditis (active/healed) & $17(4.8),(3[0.9] / 14[4.0])$ \\
\hline Ischemic & $3(0.9)$ \\
\hline Rheumatic & $3(0.9)$ \\
\hline Congenital & $1(0.3)$ \\
\hline Tethering & $16(4.6)$ \\
\hline \multicolumn{2}{|l|}{ Main lesion } \\
\hline Anterior leaflet & $78(22.2)$ \\
\hline Posterior leaflet & $163(46.4)$ \\
\hline Bilateral leaflets & $110(31.4)$ \\
\hline
\end{tabular}

Categorical data are presented as number (\%) of patients, and continuous data are presented as median (interquartile range). $B M I$, Body mass index; $B S A$, body surface area; $C r$, creatinine; $L V$, left ventricular; $N Y H A$, New York Heart Association.

infarction secondary to a left circumflex artery lesion. However, the causes of the other ventricular ruptures were unknown, and we performed left ventricular repair without MV replacement. Four patients developed a deep sternal wound infection and 6 developed pneumonia. Five patients required prolonged mechanical ventilation ( $>72$ hours), including 1 with a tracheotomy, 9 with acute renal failure (4 undergoing continuous hemodialysis), 1 with a cerebral
TABLE 2. Intraoperative and postoperative data

\begin{tabular}{|lc}
\hline \multicolumn{1}{c}{ Variable } & \\
\hline Number of loops & $3(2-4)$ \\
\hline Additional adjustment after ink-dot marking test & $41(11.7)$ \\
\hline Loop-in-loop technique & $87(24.8)$ \\
\hline Use of fixing suture needles & $71(20.2)$ \\
\hline Commissural edge-to-edge suturing & $232(66.1)$ \\
\hline Secondary chordal cutting & $11(3.1)$ \\
\hline Height reduction & $25(7.1)$ \\
\hline Patch augmentation & $8(2.3)$ \\
\hline Triangular resection & $4(1.1)$ \\
\hline Conventional/right mini-thoracotomy approach & $283(80.6) / 68(19.4)$ \\
\hline Concomitant operations & \\
\hline Tricuspid valve annuloplasty/repair & $121(34.5) / 3(0.9)$ \\
\hline Aortic valve replacement/reconstruction & $11(3.1) / 2(0.6)$ \\
\hline Coronary artery bypass grafting & $23(6.6)$ \\
\hline Maze procedure/PV isolation & $47(13.4) / 8(2.3)$ \\
\hline Ascending aorta replacement & $2(0.6)$ \\
\hline ASD closure/VSD closure & $7(2.0) / 1(0.3)$ \\
\hline Operation time, min & $289(243-344)$ \\
\hline Cardiopulmonary bypass time, min & $173(136-210)$ \\
\hline Aortic crossclamp time, min & $133(108-160)$ \\
\hline Second arrest & $35(10.0)$ \\
\hline Systolic anterior motion & $41(11.7)$ \\
\hline Relief by volume overload/height reduction & $11(3.1) / 3(0.9)$ \\
\hline Requirement for IABP & $4(1.1)$ \\
\hline Postoperative ejection fraction, \% & $38.0(2.0)$ \\
\hline Postoperative ejection fraction of $<40 \%$ & $(51.0-62.0)$ \\
\hline Postoperative LV diastolic dimension, mm & $47.0(43.0-51.0)$ \\
\hline Postoperative mean pressure gradient, mm Hg & $3.0)$ \\
\hline Mild residual MR & \\
\hline Moderate residual MR & \\
\hline Mortality & \\
\hline
\end{tabular}

Categorical data are presented as number (\%) of patients, and continuous data are presented as median (interquartile range). $P V$, Pulmonary vein; $A S D$, atrial septal defect; $V S D$, ventricular septal defect; $I A B P$, intra-aortic balloon pumping; $L V$, left ventricular; $M R$, mitral regurgitation.

infarction, and 1 with complete atrioventricular block. Immediate postoperative transthoracic echocardiography during hospitalization showed trivial MR in 285 patients, mild residual MR in 64, and moderate residual MR in 2. One patient with moderate residual MR underwent MV repair for MR caused by papillary muscle rupture due to acute coronary artery ischemia, and the other patient who was undergoing hemodialysis underwent the loop technique with 
patch augmentation of the posterior leaflet because of shortening of the posterior leaflet. The acute coronary ischemia was caused by fixation of the loop set to the ischemic papillary muscle; this patient required a reoperation for recurrent MR 8 months postoperatively. The mean pressure gradient of the MV was $3.2 \pm 1.4 \mathrm{~mm} \mathrm{Hg}$ (median [interquartile range], 3.0 [2.0-4.0] $\mathrm{mm} \mathrm{Hg}$ ).

\section{Long-Term Outcomes}

The 1-, 5-, and 10-year postoperative cumulative survival rate was $99.1 \%, 95.1 \%$, and $93.1 \%$, respectively. The $1-$, 3-, 5-, and 10-year postoperative cumulative incidence of reoperation with death as the competing variable was $1.2 \%, 2.3 \%, 3.0 \%$, and $7.4 \%$, respectively (Table 3 and Figure 4, A). Only 10 patients underwent MV replacement with a mechanical or bioprosthetic valve, and 1 patient underwent MV re-repair for recurrent MR. The cause of recurrent MR was progression of degenerative change in the MV leaflets and subvalvular apparatus in 9 patients and ring detachment in 1 patient. Among the patients with progression of degenerative change, 1 patient with Barlow's disease who did not undergo mitral annuloplasty developed loop rupture due to disease progression, 1 underwent the loop technique with fixation on the contralateral papillary muscle over the midline, and 2 had ischemic heart disease with tethering of the posterior leaflet and posterior leaflet prolapse caused by papillary muscle rupture. The 1-, 3-, 5 -, and 9-year cumulative incidence of reoperation with death as the competing variable was $0.0 \%, 2.1 \%, 2.1 \%$, and $5.9 \%$ for anterior lesions; $1.3 \%, 1.3 \%, 2.6 \%$, and $9.1 \%$ for posterior lesions; and $1.8 \%, 4.1 \%, 4.1 \%$, and $4.1 \%$ for bilateral lesions, respectively. There was no significant difference in this rate for each lesion type $(P=.697)$ (Figure $4, B)$. The cumulative incidence of reoperation was comparable between patients who did and did not require an additional repair technique after the ink-dot marking test $(P=.290)$ (Figure $4, C)$. Only 18 patients had more than moderate-to-severe recurrent MR. The 1-, ;3-, 5-, and 10-year postoperative cumulative incidence of more-than moderate-to-severe recurrent MR was $1.6 \%, 3.6 \%, 6.0 \%$, and $19.8 \%$, respectively (Table 4 and
Figure 5, A). There was no significant difference in this rate for each lesion type $(P=.822)$ (Figure $5, B)$ or between patients who did and did not require an additional repair technique after the ink-dot marking test $(P=.932)$ (Figure 5, C). The risk factors for more than moderate to severe recurrent MR are presented in Tables 5 and 6 .

\section{DISCUSSION}

The loop technique has gained attention because it is easily adjustable and preserves the subvalvular apparatus without leaflet resection. This technique is associated with a low MV pressure gradient facilitated by better leaflet mobility and MV coaptation. Intraoperative assessment is important to reduce the incidence of more than mild residual MR, which is associated with recurrent MR., ${ }^{3,11-13}$ The ink test and water saline test are a major assessment tools to identify the coaptation length of the MV leaflets and the leakage point. ${ }^{10}$ Lawrie and colleagues ${ }^{14}$ obtained good results of neochordal repair with ink-dot marking to align the free edges of the leaflets to the same plane as the opposite segment in patients with Barlow's disease. Our ink-dot marking test slightly differs with respect to our mark in the center of the posterior leaflet versus Lawrie's dots along the upper margin of the rough zone in the posterior leaflet. Our strategy provided good early- and long-term results with a high rate of less-than-mild residual MR and a very low rate of reoperation for recurrent MR.

Our concept of MV repair with the loop technique consists of aligning the leaflet height by the ink-dot marking line, which provides a good coaptation length and configuration of the MV associated with low residual MR. If leaflet height alignment is unsuccessful, we adjust the fixing point of the loop on the leaflet or the loop length by the loop-inloop technique, or we perform additional neochordal repair to easily align the leaflet height. The loop technique with ink-dot marking test was successful in $99.4 \%$ of patients who had less-than-mild residual MR before discharge. Kuntze and colleagues ${ }^{15}$ reported that MV repair with the loop technique resulted in less-than-mild residual MR in $96 \%$ of patients on predischarge echocardiography. We obtained superior or equal results by the loop technique with the

TABLE 3. Cumulative incidence of reoperation

\begin{tabular}{lcccccc}
\hline & $\mathbf{1 ~ y}$ & $\mathbf{3 ~ y}$ & $\mathbf{5 ~ y}$ & $\mathbf{7} \mathbf{y}$ & $\mathbf{9} \mathbf{y}$ & $\mathbf{1 0} \mathbf{y}$ \\
\hline Whole & $1.2(0.004-0.028)$ & $2.3(0.010-0.046)$ & $3.0(0.013-0.058)$ & $4.0(0.018-0.076)$ & $7.4(0.022-0.168)$ & $7.4(0.022-0.168)$ \\
AL & $0(0.000-0.000)$ & $2.1(0.002-0.096)$ & $2.1(0.002-0.096)$ & $5.9(0.009-0.182)$ & $5.9(0.009-0.182)$ & $5.9(0.009-0.182)$ \\
PL & $1.3(0.003-0.042)$ & $1.3(0.003-0.042)$ & $2.6(0.006-0.073)$ & $2.6(0.006-0.073)$ & $9.1(0.013-0.268)$ & $9.1(0.013-0.268)$ \\
BL & $1.8(0.004-0.059)$ & $4.1(0.013-0.095)$ & $4.1(0.013-0.095)$ & $4.1(0.013-0.095)$ & $4.1(0.013-0.095)$ & NA \\
None & $1.0(0.003-0.028)$ & $2.3(0.009-0.047)$ & $3.0(0.013-0.060)$ & $4.1(0.017-0.080)$ & $4.1(0.017-0.080)$ & $4.1(0.017-0.080)$ \\
Add & $2.4(0.002-0.112)$ & $2.4(0.002-0.112)$ & $2.4(0.002-0.112)$ & $2.4(0.002-0.112)$ & NA & NA \\
\hline
\end{tabular}

Values are \% (95\% confidence interval). The postoperative reoperation rates are expressed as the cumulative incidence with death as the competing variable. AL, Anterior leaflet; $P L$, posterior leaflet; $B L$, bilateral leaflet; None, none adjustment after ink-dot marking test; Add, adjustment after ink-dot marking test; $N A$, not applicable. 
(\%)

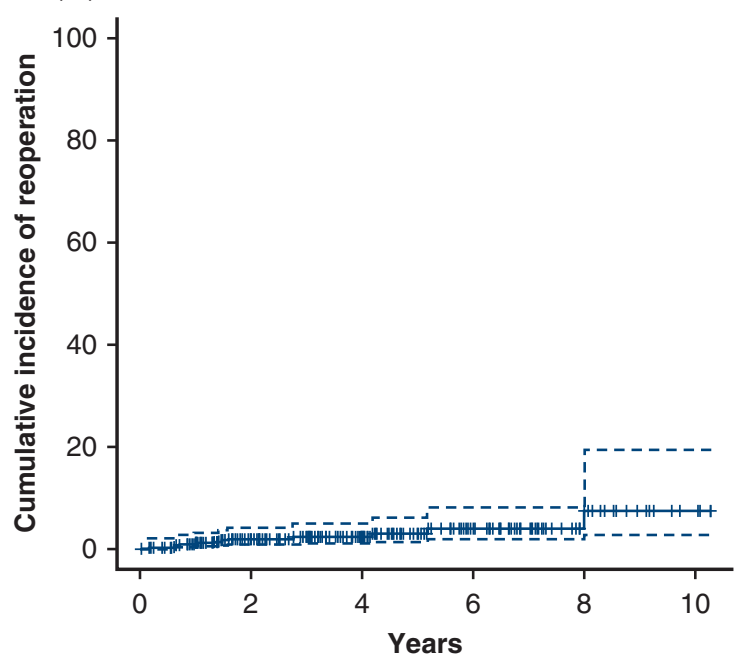

Number at risk

351

A

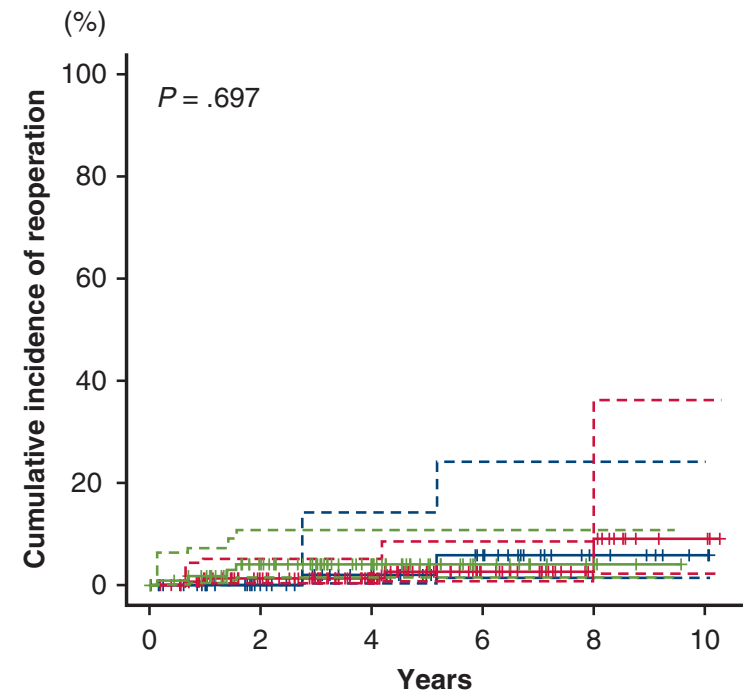

Number at risk

$\begin{array}{ccccccc}\text { AL } & 78 & 51 & 34 & 21 & 8 & 2 \\ -\mathrm{PL} & 163 & 119 & 82 & 37 & 14 & 3 \\ \mathrm{BL} & 110 & 76 & 42 & 12 & 4 & 0\end{array}$

B

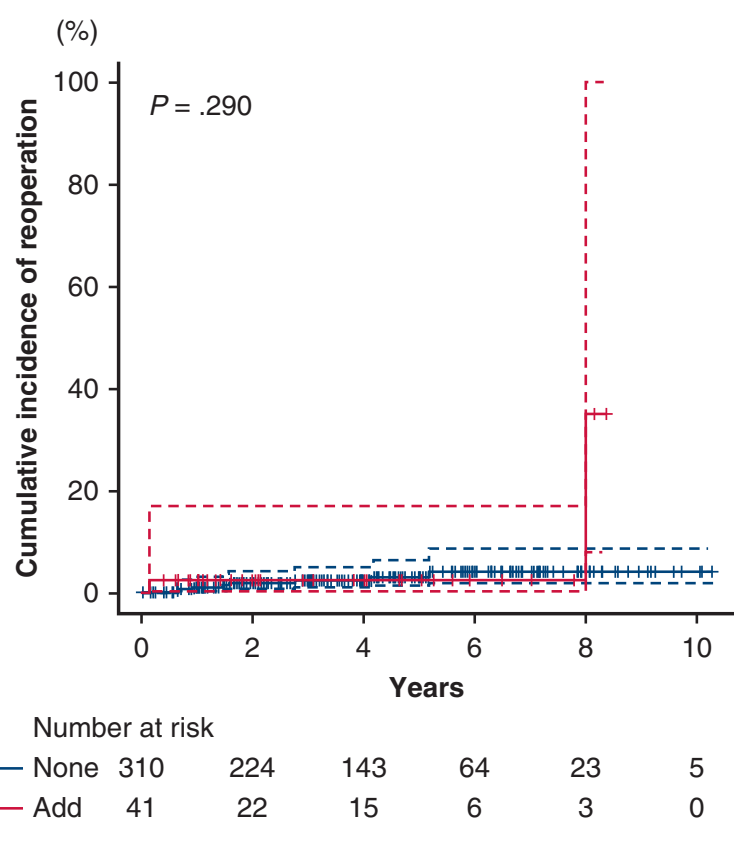

FIGURE 4. Cumulative incidence of reoperation with death as the competing variable. A, All cases. B, Comparison among lesions of mitral valve leaflets. $\mathrm{C}$, Comparison between patients with (add) and without (none) a requirement for additional repair after the ink-dot marking test. The broken lines indicate the $95 \%$ confidence interval. $A L$, Anterior leaflet $P L$, posterior leaflet; $B L$, bilateral leaflet.

ink-dot marking test. In addition, we assessed the requirement for intraoperative second arrest and the long-term outcomes between patients who did and did not require additional repair after the ink-dot marking test. Although no significant difference was found in second arrest between the 2 groups, no adjustment in the patients who had irregular height of leaflet by the ink-dot marking test may increase the need for second arrest. Moreover, no significant differences were found in the rate of reoperation or more-than moderate-to-severe recurrent MR between the 2 
TABLE 4. Cumulative incidence of more than moderate-to-severe recurrent mitral valve regurgitation

\begin{tabular}{lrrrrr}
\hline & $\mathbf{1 ~ y}$ & $\mathbf{3 ~ y}$ & $\mathbf{5} \mathbf{y}$ & $\mathbf{7 ~ y}$ & $\mathbf{1 0} \mathbf{y}$ \\
\hline Whole & $1.6(0.002-0.030)$ & $3.6(0.014-0.058)$ & $6.0(0.025-0.093)$ & $9.9(0.034-0.159)$ & $19.8(0.066-0.312)$ \\
AL & $0(0.000-0.000)$ & $2.1(0.002-0.096)$ & $2.1(0.002-0.096)$ & $5.9(0.009-0.182)$ & $5.9(0.009-0.182)$ \\
PL & $1.3(0.003-0.042)$ & $1.3(0.003-0.042)$ & $2.6(0.006-0.073)$ & $2.6(0.006-0.073)$ & $9.1(0.013-0.268)$ \\
BL & $1.8(0.004-0.059)$ & $4.1(0.013-0.095)$ & $4.1(0.013-0.095)$ & $4.1(0.013-0.095)$ & NA \\
None & $1.0(0.003-0.028)$ & $2.3(0.009-0.047)$ & $3.0(0.013-0.060)$ & $4.1(0.017-0.080)$ & $4.1(0.017-0.080)$ \\
Add & $2.4(0.002-0.112)$ & $2.4(0.002-0.112)$ & $2.4(0.002-0.112)$ & $2.4(0.002-0.112)$ & NA \\
\hline
\end{tabular}

Values are $\%$ (95\% confidence interval). The postoperative rates of more than moderate-to-severe recurrent mitral valve regurgitation are expressed as the cumulative incidence. $A L$, Anterior leaflet; $P L$, posterior leaflet; $B L$, bilateral leaflet; None, none adjustment after ink-dot marking test; $A d d$, adjustment after ink-dot marking test; $N A$, not applicable.

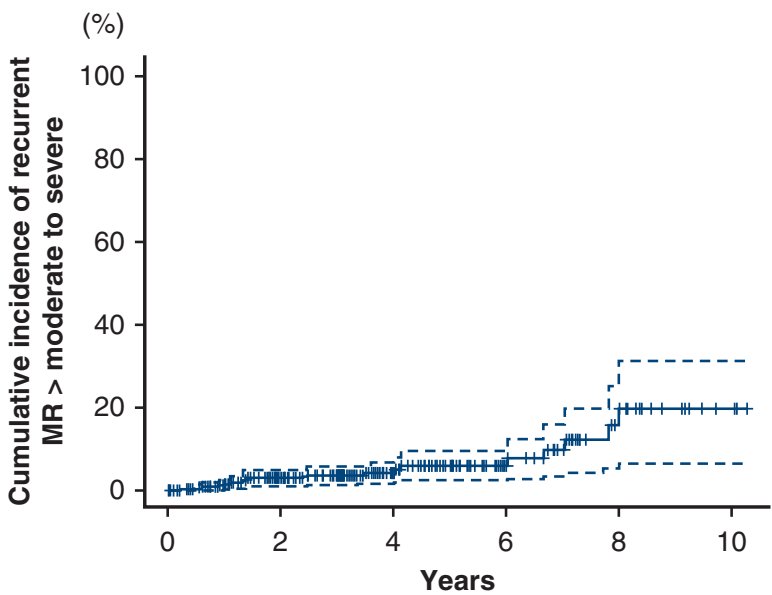

Number at risk 351 227

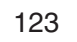

53

A

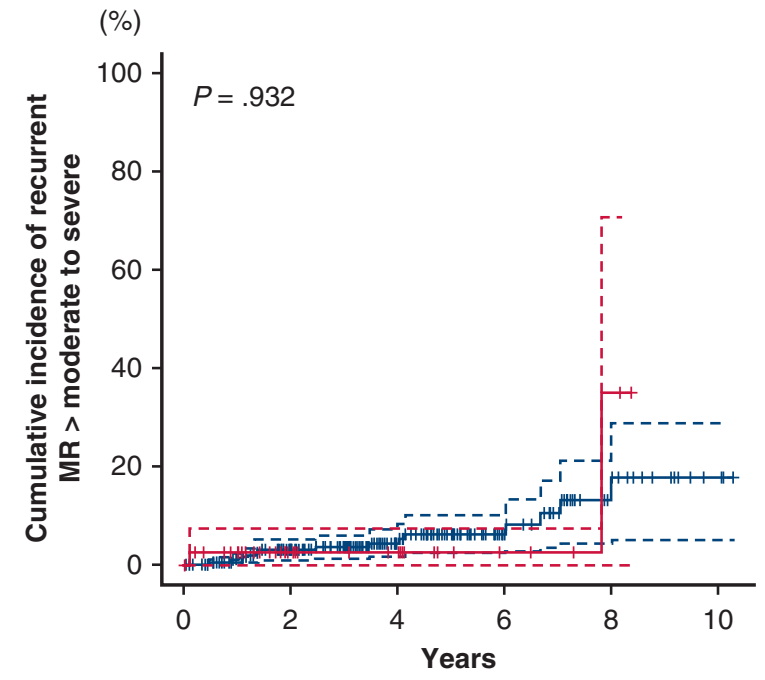

Number at risk

\begin{tabular}{lcccccc}
\hline None & 310 & 207 & 109 & 48 & 19 & 5 \\
C Add & 41 & 20 & 14 & 5 & 2 & 0
\end{tabular}

FIGURE 5. Cumulative incidence of more than moderate to severe recurrent mitral valve regurgitation. A, All cases. B, Comparison among lesions of mitral valve leaflets. C, Comparison between patients with (add) and without (none) a requirement for additional repair after the ink-dot marking test. The broken lines indicate the $95 \%$ confidence interval. $M R$, Mitral regurgitation; $A L$, anterior leaflet; $P L$, posterior leaflet; $B L$, bilateral leaflet. 
TABLE 5. Cox regression analysis of risk factors for more than moderate-to-severe recurrent MR

\begin{tabular}{|c|c|c|}
\hline Variables & Hazard ratio* $(95 \%$ CI $)$ & $P$ value \\
\hline Sex, male & $1.54(0.568-4.168)$ & .400 \\
\hline BSA & $1.55(0.126-18.91)$ & .734 \\
\hline Hypertension & $1.49(0.545-4.076)$ & .438 \\
\hline Hemodialysis & $<0.01$ (0.000-Inf) & .998 \\
\hline Preoperative ejection fraction of $<40 \%$ & $<0.01$ (0.000-Inf) & .998 \\
\hline Preoperative LV diastolic dimension of $>65 \mathrm{~mm}$ & $1.28(0.167-9.745)$ & .841 \\
\hline Previous cardiac surgery & $7.76(0.982-61.30)$ & .052 \\
\hline Barlow's disease & $1.04(0.137-7.93)$ & .967 \\
\hline Tethering & $3.88(0.454-33.18)$ & .216 \\
\hline Main lesion, posterior leaflet & $1.51(0.447-5.086)$ & .509 \\
\hline Main lesion, bilateral leaflets & $1.01(0.246-4.107)$ & .994 \\
\hline Additional adjustment ink-dot marking test & $1.15(0.260-5.076)$ & .855 \\
\hline Loop-in-loop technique & $4.48(1.655-12.13)$ & .003 \\
\hline Height reduction & $4.17(1.132-15.40)$ & .032 \\
\hline Patch augmentation & $<0.01$ (0.000-Inf) & .998 \\
\hline Fixing suture needles & $0.62(0.140-2.703)$ & .521 \\
\hline Triangular resection & $<0.01$ (0.000-Inf) & .998 \\
\hline Mitral annular repair & $0.01(0.001-0.137)$ & $<.001$ \\
\hline Right mini-thoracotomy approach & $1.83(0.462-7.260)$ & .389 \\
\hline Concomitant operations & $0.54(0.191-1.501)$ & .235 \\
\hline Second arrest & $2.26(0.734-6.950)$ & .155 \\
\hline Systolic anterior motion & $<0.01$ (0.000-Inf) & .998 \\
\hline Postoperative ejection fraction of $<40 \%$ & $<0.01$ (0.000-Inf) & .998 \\
\hline More than or equal to mild residual MR & $16.57(5.614-48.93)$ & $<.001$ \\
\hline Postoperative persistent atrial fibrillation & $2.19(0.565-8.48)$ & .257 \\
\hline
\end{tabular}

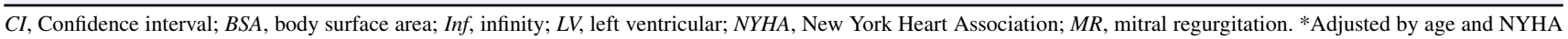
class $>$ III

groups. This suggests that aligning the mitral leaflet height is also associated with a low rate of residual MR, although the coaptation length is apparently important to obtain good results of MV repair.

A discrepancy exists between direct visual assessment during the ink-dot marking test with the water saline test and intraoperative transesophageal echocardiography, which sometimes requires second arrest with additional MV repair for residual MR. In our MV repair, 35 patients
$(10.0 \%)$ required a second arrest for residual MR, and we commonly identified misalignment of the MV height that required loop adjustment or additional neochordal repair. The reason may be the geometric differences in the mitral complex apparatus between the dilated left ventricle by water saline injection under a nonbeating heart and the contractile left ventricle under a beating heart, and the water saline injection may be insufficient at first arrest. Other assessment methods, such as assessment of a beating

TABLE 6. Final Cox regression analysis of risk factors for more than moderate-to-severe recurrent MR

\begin{tabular}{lcr}
\hline \multicolumn{1}{c}{ Variables } & Hazard ratio (95\% CI) & $\boldsymbol{P}$ value \\
\hline Loop-in-loop technique & $3.90(1.301-11.67)$ & .015 \\
Height reduction & $1.71(0.364-8.081)$ & .496 \\
Mitral annular repair & $0.23(0.019-2.776)$ & .247 \\
More than or equal to mild residual MR & $12.8(4.443-36.81)$ & $<.001$ \\
\hline
\end{tabular}

CI, Confidence interval; $M R$, mitral regurgitation. 
heart by antegrade or retrograde coronary perfusion, have recently been reported. ${ }^{16-20}$ These assessment methods showed few differences between assessment of a beating heart and intraoperative transesophageal echocardiography. However, assessment with antegrade coronary perfusion has risks of air embolization and technical difficulty under the fibrillated state and blood filling the operative field. Tachibana and colleagues ${ }^{20}$ performed MV repair under cardiac arrest and assessment under a beating heart by warm retrograde coronary perfusion during aortic clamping, which improves the aforementioned problems. Therefore, a retrograde cardioprotective beating test may be useful to reduce the second pump arrest.

Left ventricular wall rupture and left circumflex artery injury are very rare complications after MV repair. We experienced 3 cases of left ventricular rupture in patients who underwent MV repair in the primary stage, and their left ventricular rupture may have therefore been derived from technical issues such as injury by the left vent tube, overdilation of the left ventricle with saline, or suturing of the MV annuloplasty. Moreover, 5 patients developed postoperative myocardial infarction. According to the 2010 Society of Thoracic Surgeons database, the risk of perioperative myocardial infarction, which may be due to circumflex artery injury, is $2.2 \%$ among patients undergoing MV repair. ${ }^{21}$ Recent reports have shown that the risk of left circumflex artery injury in patients undergoing MV repair ranges from $0.3 \%$ to $1.8 \%$; however, this may be underestimated because of undetected silent ischemia, confusion with other causes of ischemia, no routine measurement of cardiac enzymes, and other possible factors. $^{21,22}$ Our results also showed that the incidence of postoperative myocardial infarction was $1.4 \%$, including a $0.9 \%$ incidence of injury of the left circumflex artery caused by mitral valve annuloplasty, which is consistent with the aforementioned reports. Previously reported risk factors for left circumflex artery injury include a short distance between the coronary artery and MV annulus of the anterior commissure or P1 segment, tissue distortion and kinking of the artery by large suture bites in the MV annulus or extensive quadrangular resection, and the use of a smaller ring for a large MV annulus. ${ }^{21,23}$ Our 3 cases might have been caused by large, deep suture bites during MV annuloplasty with a very short distance between the left circumflex coronary artery and the MV annulus. Furthermore, a recent study revealed that in some patients, the circumflex coronary artery coursed near the MV annulus of the P1 segment, especially in patients with a left dominant coronary artery, as shown by 3-dimensional computed tomography. ${ }^{24}$ Such preoperative assessment may be useful to avoid injury of the left circumflex artery.

Our loop technique with the ink-dot marking test provided good long-term outcomes and a very low reoperation rate comparable with previous reports. ${ }^{25,26}$ Previously reported risk factors for reoperation include anterior leaflet lesions and no ring annuloplasty. ${ }^{2,3,27,28} \mathrm{We}$ also showed that MV repair with no ring for Barlow's disease always required reoperation for recurrent MR. However, the absence of significant differences in reoperation and recurrent MR for each lesion type may have occurred because we used more than 2 loops for each leaflet lesion, strengthening the support of the leaflets to prevent reprolapse. Our reoperation cases were associated with severe ischemic heart disease, including ruptured papillary muscles and posterior leaflet shortening with severe tethering, as well as MV repair without ring plasty for Barlow's disease. Thus, reoperation after MV repair may be associated with the technical issues and inherent difficulty of MV repair.

The present study has inherent limitations. First, this was a retrospective observational analysis. Second, some surgeons performed MV repair with the loop technique for MR. However, we attained secure and excellent results of MV repair with the loop technique, indicating high reproducibility and reliability of this technique, with a $>10$ year postoperative follow-up. Further follow-up may be required to evaluate the availability of MV repair with the loop technique for MR.

\section{CONCLUSIONS}

The loop technique with the ink-dot marking test for MR provided good early- and long-term results. This may be a reliable technique for decreasing residual MR and increasing the success rate of MV repair.

\section{Conflict of Interest Statement}

The authors reported no conflicts of interest.

The Journal policy requires editors and reviewers to disclose conflicts of interest and to decline handling or reviewing manuscripts for which they may have a conflict of interest. The editors and reviewers of this article have no conflicts of interest.

We thank Angela Morben, DVM, ELS, from Edanz Group (www.edanzediting.com/ac), for editing a draft of this manuscript. We also thank Professor Ayumi Shintani, PhD, from the Department of Medical Statistics, Osaka City University Graduate School of Medicine, Osaka, Japan, for assisting with the statistical analysis.

\section{References}

1. Salvador L, Mirone S, Bianchini R, Regesta T, Patelli F, Minniti G, et al. A 20year experience with mitral valve repair with artificial chordae in 608 patients. $J$ Thorac Cardiovasc Surg. 2008;135:1280-7.

2. David TE, Armstrong S, Ivanov J. Chordal replacement with polytetrafluoroethylene sutures for mitral valve repair: a 25-year experience. J Thorac Cardiovasc Surg. 2013;145:1563-9.

3. Hata H, Fujita T, Shimahara Y, Sato S, Ishibashi-Ueda H, Kobayashi J. A 25-year study of chordal replacement with expanded polytetrafluoroethylene in mitral valve repair. Interact Cardiovasc Thorac Surg. 2015;20:463-8; discussion 468. 
4. De Bonis M, Lapenna E, Taramasso M, La Canna G, Buzzatti N, Pappalardo F, et al. Very long-term durability of the edge-to-edge repair for isolated anterior mitral leaflet prolapse: up to 21 years of clinical and echocardiographic results. J Thorac Cardiovasc Surg. 2014;148:2027-32.

5. Perier P, Hohenberger W, Lakew F, Batz G, Urbanski P, Zacher M, et al. Toward a new paradigm for the reconstruction of posterior leaflet prolapse: midterm results of the "respect rather than resect" approach. Ann Thorac Surg. 2008;86:718-25; discussion 718-25.

6. Kitahara H, Murata M, Okamoto K, Kudo M, Yoshitake A, Tsuruta H, et al. Preservation of mobility of the posterior mitral leaflet after mitral valve repair with neochordae using loop technique. Circ J. 2016;80:663-7.

7. Jahren SE, Hurni S, Heinisch PP, Winkler B, Obrist D, Carrel T, et al. Transvalvular pressure gradients for different methods of mitral valve repair: only neochordoplasty achieves native valve gradients. Interact Cardiovasc Thorac Surg. 2018; 26:248-55

8. von Oppell UO, Mohr FW. Chordal replacement for both minimally invasive and conventional mitral valve surgery using premeasured Gore-Tex loops. Ann Thorac Surg. 2000;70:2166-8.

9. Shibata T, Kato Y, Motoki M, Takahashi Y, Morisaki A, Nishimura S, et al. Mitra valve repair with loop technique via median sternotomy in 180 patients. Eur J Cardiothorac Surg. 2015;47:491-6.

10. Anyanwu AC, Adams DH. The intraoperative "ink test": a novel assessment tool in mitral valve repair. J Thorac Cardiovasc Surg. 2007;133:1635-6.

11. Ender J, Sgouropoulou S. Value of transesophageal echocardiography (TEE) guidance in minimally invasive mitral valve surgery. Ann Cardiothorac Surg. 2013:2:796-802.

12. Maisano F, Caldarola A, Blasio A, De Bonis M, La Canna G, Alfieri O. Midterm results of edge-to-edge mitral valve repair without annuloplasty. J Thorac Cardiovasc Surg. 2003;126:1987-97.

13. De Bonis M, Lapenna E, Maisano F, Barili F, La Canna G, Buzzatti N, et al. Long-term results ( $\leq 18$ years) of the edge-to-edge mitral valve repair without annuloplasty in degenerative mitral regurgitation: implications for the percutaneous approach. Circulation. 2014;130:S19-24.

14. Lawrie GM, Earle EA, Earle NR. Nonresectional repair of the barlow mitral valve: importance of dynamic annular evaluation. Ann Thorac Surg. 2009;88: 1191-6.

15. Kuntze T, Borger MA, Falk V, Seeburger J, Girdauskas E, Doll N, et al. Early and mid-term results of mitral valve repair using premeasured Gore-Tex loops ('loop technique'). Eur J Cardiothorac Surg. 2008;33: 566-72.

16. Watanabe T, Arai H. Leakage test during mitral valve repair. Gen Thorac Cardiovasc Surg. 2014;62:645-50.
17. Sundt TM III, Khaghani A, Yacoub MH. Alternative technique for assessment and repair of the mitral valve. Ann Thorac Surg. 1996;61:1552-4.

18. Miyairi T, Matsumoto J, Tanaka K, Mizuno A. Intraoperative assessment of func tioning mitral valve. Ann Thorac Surg. 1996;61:743-5.

19. Miyairi T, Miura S, Taketani T, Kusuhara T, Lee Y, Unai S, et al. Intraoperative assessment for mitral valve competency in a beating heart under retrograde coronary perfusion. Int Heart J. 2013;54:192-5.

20. Tachibana K, Higami T, Miyaki Y, Takagi N. Novel intraoperative evaluation for mitral valve regurgitation: retrograde cardioprotective beating test. Eur J Cardiothorac Surg. 2013;44:375-6.

21. Coutinho GF, Leite F, Antunes MJ. Circumflex artery injury during mitral valve repair: not well known, perhaps not so infrequent-lessons learned from a 6-case experience. J Thorac Cardiovasc Surg. 2017;154:1613-20.

22. Aybek T, Risteski P, Miskovic A, Simon A, Dogan S, Abdel-Rahman U, et al Seven years' experience with suture annuloplasty for mitral valve repair J Thorac Cardiovasc Surg. 2006;131:99-106.

23. Virmani R, Chun P, Parker J, McAllister HA Jr. Suture obliteration of the circumflex coronary artery in three patients undergoing mitral valve operation. Role of left dominant or codominant coronary artery. J Thorac Cardiovasc Surg. 1982; 84:773-8.

24. Ghersin N, Abadi S, Sabbag A, Lamash Y, Anderson RH, Wolfson H, et al. The three-dimensional geometric relationship between the mitral valvar annulus and the coronary arteries as seen from the perspective of the cardiac surgeon using cardiac computed tomography. Eur J Cardiothorac Surg. 2013; 44:1123-30.

25. Seeburger J, Falk V, Borger MA, Passage J, Walther T, Doll N, et al. Chordae replacement versus resection for repair of isolated posterior mitral leaflet prolapse: à ègalité. Ann Thorac Surg. 2009:87:1715-20.

26. Borger MA, Kaeding AF, Seeburger J, Melnitchouk S, Hoebartner M, Winkfein $\mathrm{M}$, et al. Minimally invasive mitral valve repair in Barlow's disease: early and long-term results. J Thorac Cardiovasc Surg. 2014; 148:1379-85.

27. David TE, Ivanov J, Armstrong S, Christie D, Rakowski H. A comparison of outcomes of mitral valve repair for degenerative disease with posterior, anterior, and bileaflet prolapse. J Thorac Cardiovasc Surg. 2005;130:1242-9.

28. Flameng W, Meuris B, Herijgers P, Herregods MC. Durability of mitral valve repair in Barlow disease versus fibroelastic deficiency. J Thorac Cardiovasc Surg. 2008;135:274-82.

Key Words: ink-dot marking test, mitral valve repair, loop technique 


\section{APPENDIX 1: SURGICAL TECHNIQUES \\ Conventional Approach}

A full median sternotomy was performed with the patient under general anesthesia. After systemic heparinization, we established cardiopulmonary bypass in a standard fashion involving ascending aortic or aortic arch cannulation and bicaval venous cannulations to the superior vena cava and inferior vena cava. The left atrial or ventricular vent was inserted via the right upper pulmonary vein. After aortic crossclamping, cardiac arrest was performed by identical cold-blood antegrade and retrograde cardioplegia, followed by intermittent antegrade or retrograde cardioplegia.

\section{Right Mini-Thoracotomy Approach (Minimally Invasive Cardiac Surgery)}

We performed a right mini-thoracotomy with the patient under general anesthesia with left double-lumen endotracheal tube ventilation. After systemic heparinization, cardiopulmonary bypass was established with an arterial cannula to the right common femoral artery and a venous cannula to the right atrium through the right common femoral vein. To ensure sufficient arterial flow or venous drainage, we also inserted an arterial cannula into the right axillary artery or left femoral artery and a venous cannula into the superior vena cava through the right jugular vein in some patients. Vacuum-assisted venous drainage was applied. A left atrial vent was inserted via the right upper pulmonary vein. mitral valve repair was performed thoracoscopically. After aortic crossclamping, identical cold-blood cardioplegia was administered into the aortic root, followed by intermittent antegrade cardioplegia. 